\title{
Low-chloride versus high-chloride hypertonic solution for the treatment of subarachnoid hemorrhage-related complications (The ACETatE trial): study protocol for a pilot randomized controlled trial
}

Ofer Sadan ${ }^{1 *} \mathbb{D}$, Owen Samuels ${ }^{1}$, William H. Asbury ${ }^{2}$, John J. Hanfelt ${ }^{3}$ and Kai Singbart ${ }^{4^{*}}$

\begin{abstract}
Background: Aneurysmal subarachnoid hemorrhage (aSAH) is a life-threatening condition that results from a ruptured cerebral vessel. Cerebral edema and vasospasm are common complications and frequently require treatment with hypertonic solutions, in particular hypertonic sodium chloride $(\mathrm{NaCl})$. We have previously shown that hyperchloremia in patients with aSAH given hypertonic $\mathrm{NaCl}$ is associated with the development of acute kidney injury (AKI), which leads to higher morbidity and mortality. Our current trial aims to study the effect of two hypertonic solutions with different chloride content on serum chloride concentrations in patients with aSAH who are at risk for AKl.
\end{abstract}

Methods: A low ChloridE hyperTonic solution for brain Edema (ACETatE) is a single center, double-blinded, doubledummy pilot trial comparing bolus doses of $23.4 \% \mathrm{NaCl}$ and $16.4 \% \mathrm{NaCl} / \mathrm{Na}$-Acetate for the treatment of cerebral edema in patients with aSAH. All patients will be enrolled within $36 \mathrm{~h}$ following admission. Randomization will occur once patients who receive hypertonic treatment for cerebral edema develop hyperchloremia (serum $\mathrm{Cl}^{-}$ concentration $\geq 109 \mathrm{mmol} / \mathrm{L}$ ). Subsequent treatment will consist of either $\mathrm{NaCl} 23.4 \%$ or $\mathrm{NaCl} / \mathrm{Na}$-Acetate $16.4 \%$. The primary outcome of this study will be the change in serum $\mathrm{Cl}^{-}$concentrations during treatment. Secondary outcomes will include incidence of AKI, mortality, changes in intracranial pressure, and extent of hypernatremia.

\footnotetext{
*Correspondence: ofer.sadan@gmail.com; ks.ms@posteo.de

'Department of Neurology and Neurosurgery, Division of Neurocritical Care, Emory University Hospital and Emory School of Medicine, 1364 Clifton Road NE, Atlanta, GA 30322, USA

${ }^{4}$ Department of Critical Care Medicine, Mayo Clinic, Phoenix, AZ 85054, USA

Full list of author information is available at the end of the article
}

(c) The Author(s). 2018 Open Access This article is distributed under the terms of the Creative Commons Attribution 4.0 International License (http://creativecommons.org/licenses/by/4.0/), which permits unrestricted use, distribution, and reproduction in any medium, provided you give appropriate credit to the original author(s) and the source, provide a link to the Creative Commons license, and indicate if changes were made. The Creative Commons Public Domain Dedication waiver (http://creativecommons.org/publicdomain/zero/1.0/) applies to the data made available in this article, unless otherwise stated. 


\begin{abstract}
(Continued from previous page)
Discussion: In patients with aSAH, hyperchloremia is a known risk factor for subsequent development of AKI. The primary goal of this pilot study is to determine the effect of two hypertonic solutions with different $\mathrm{Cl}^{-}$content on serum $\mathrm{Cl}^{-}$concentrations in patients with aSAH who have already developed hyperchloremia. Data will be collected prospectively to determine the extent to which the choice of hypertonic saline solution affects subsequent serum $\mathrm{Cl}^{-}$concentrations and the occurrence of AKI. This approach will allow us to obtain preliminary data to design a large randomized trial assessing the effects of chloride-sparing hypertonic solutions on development of AKI in patients with SAH. This pilot study is the first to prospectively evaluate the relationship between hypertonic solution chloride content and its effect on serum electrolytes and renal function in aSAH patients at risk of AKI due to hyperchloremia.
\end{abstract}

Trial registration: Clinicaltrials.gov, NCT03204955. Registered on 28 June 2017.

Keywords: Subarachnoid hemorrhage, Osmotherapy, Hypertonic NaCl, Acute kidney injury, Hyperchloremia,

\section{Background}

Aneurysmal subarachnoid hemorrhage (aSAH) is a life-threatening condition that results from a rupture in a cerebral artery [1]. Risk factors include female gender, hypertension, smoking, and excessive alcohol consumption [2]. The overall incidence is estimated at 5-10 per 100,000 per year [3]. Although treatment has improved in recent years, aSAH still represents a potentially devastating clinical condition, with a reported in-hospital mortality of approximately $20 \%$ [4]. The clinical course is often complicated by aneurysm re-bleeding, cerebral vasospasm with delayed cerebral ischemia, cerebral edema, and systemic complications, such as cardiopulmonary failure, electrolyte dysregulation, infections, and acute kidney injury (AKI). Systemic complications account for up to $40 \%$ of all deteriorations during inpatient management [5]. AKI in aSAH patients is associated with a greater than four-fold increase in hospital mortality, along with a less favorable neurological recovery in survivors [6, 7].

Hyperosmolar therapy is a cornerstone in the treatment of aSAH-related cerebral edema, which occurs in approximately 20 to $30 \%$ of this patient population [8]. Osmotherapy is based on elevation of serum osmolality via hypernatremia (e.g., hypertonic $\mathrm{NaCl}$ ) or the use of an osmotically active agent (e.g., mannitol) [9]. The goal of osmotherapy is to reduce intracranial pressure and improve cerebral blood flow by raising serum osmolarity and subsequently inducing excess fluid shifts from brain tissue into the blood stream. Hypertonic sodium chloride $(\mathrm{NaCl})$ solutions, $3 \%$ to $23.4 \%$, are commonly used to induce hypernatremia, but carry the risk of significant hyperchloremia.

Intravenous chloride load has been reported to cause negative effects on blood pressure, kidney blood flow, and fluid retention in animals [10] and, subsequently, in healthy human subjects $[11,12]$. In a variety of critically ill patient populations, hyperchloremia has also been observed to directly correlate with AKI and mortality [13,
14]. Furthermore, comparative studies have noted an association between isotonic $\mathrm{NaCl}$ infusions and an increased risk of AKI and poor outcome in critically ill patients $[15,16]$. Summarizing 21 prospective studies, a meta-analysis by Krajewski et al. [17] demonstrated that high $\mathrm{Cl}^{-}$containing solutions increase the risk of AKI, the number of blood transfusions, and the need for mechanical ventilation in perioperative or critically ill patients. Surprisingly, a multicenter trial failed to show a benefit of balanced intravenous (IV) solutions, i.e., low $\mathrm{Cl}^{-}$solution, over high $\mathrm{Cl}^{-}$solutions $(\mathrm{NaCl} 0.9 \%)$ in a mixed population of critically ill patients [18]. However, even more recent publications did demonstrate favorable renal outcomes in non-critically ill [19] and critically ill [20] patients receiving balanced crystalloid solution when compared with $\mathrm{NaCl} 0.9 \%$. Since hypertonic $\mathrm{NaCl}$ solutions are not balanced solutions, it is not surprising to encounter controversy regarding their role in the development of AKI [21, 22].

In a recently published retrospective analysis of $\mathrm{SAH}$ patients, we observed correlations between hyperchloremia and AKI, and between AKI and increased morbidity and mortality. We identified treatment with hypertonic $\mathrm{NaCl}$ as a risk factor for the development of hyperchloremia [7]. Nonetheless, we were not able to show a dose-response relationship between chloride load and subsequent development of hyperchloremia [7]; instead we found great variability in chloride exposure. The large variability appeared to be related to a high incidence of cerebral salt wasting syndrome in our study population, resulting in the need for extensive sodium and volume replacement with IV fluids, especially $\mathrm{NaCl}$ solutions at various concentrations [23].

Therefore, the question arises whether avoiding further worsening of hyperchloremia by differential use of hypertonic solutions might be a better strategy to prevent AKI in critically ill patients (with SAH) than simply replacing high $\mathrm{Cl}^{-}$solutions with low $\mathrm{Cl}^{-}$solutions in all cases. 


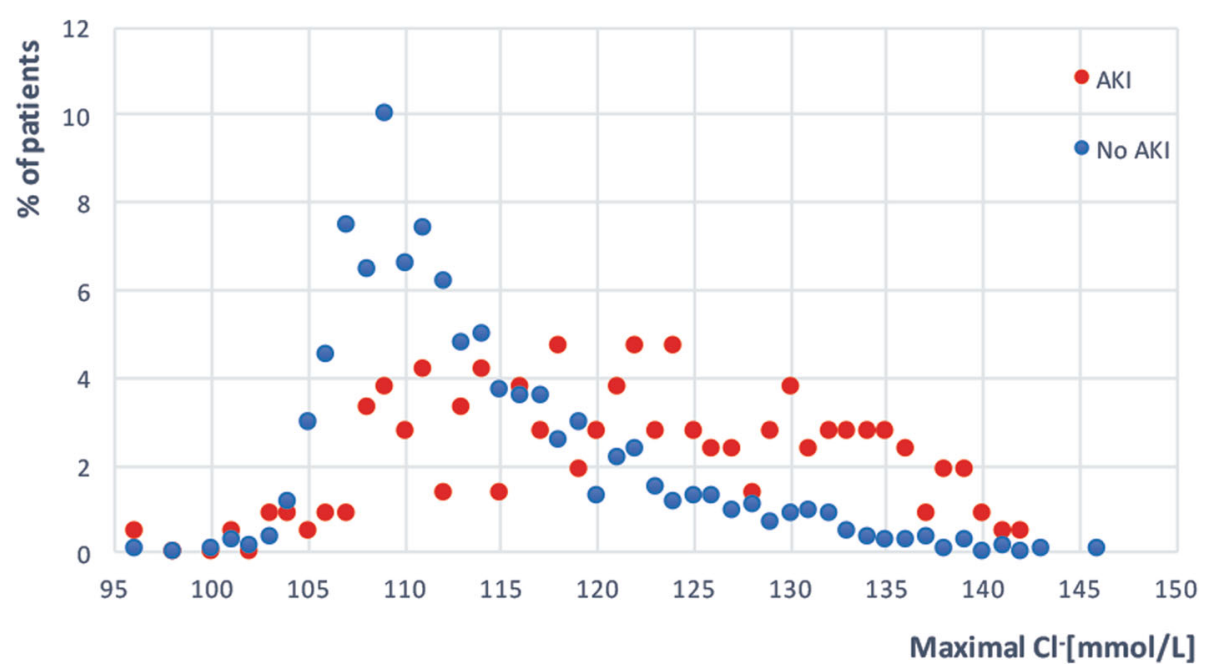

Fig. 1 Distribution of maximal chloride serum measurements between acute kidney injury (AKI) and non-AKI as a percent of patients in a retrospective cohort of SAH patients

Additional analyses of our recent study further support this approach [7]. The frequency of maximum chloride levels in patients without AKI increased up to a chloride concentration of $109 \mathrm{mmol} / \mathrm{L}$ and decreased thereafter (Fig. 1). On the contrary, the frequency of maximum $\mathrm{Cl}^{-}$ levels increased and remained elevated for serum $\mathrm{Cl}^{-}$ levels greater than $109 \mathrm{mmol} / \mathrm{L}$ in patients with AKI (Fig. 1). Moreover, only $8.5 \%$ of all AKI patients had maximum serum $\mathrm{Cl}^{-}$concentrations $<109 \mathrm{mmol} / \mathrm{L}$. By setting a threshold of $109 \mathrm{mmol} / \mathrm{L}$, we would therefore exclude only a small proportion of AKI patients. Moreover, patients without hyperchloremia appear unlikely to benefit from preventive measures with low $\mathrm{Cl}^{-}$solutions. Focusing on at-risk patients should allow us to reduce variability and consequently provide more stringent answers in this highly controversial area of AKI research.

To this end, our proposed trial described below intends to make use of the different $\mathrm{Cl}^{-}$content in $\mathrm{NaCl}$ $23.4 \%$ or $\mathrm{NaCl} / \mathrm{Na}$-Acetate $16.4 \%$ (Table 1 ) and thereby to examine the causative role of hypertonic IV solutions in the development of hyperchloremia (and subsequently
AKI) in patients with SAH. Our study design represents a double-blinded, double-dummy, pragmatic approach.

\section{Methods and study design}

\section{Study objectives}

In a single-center, double-blinded, double-dummy pilot design we will compare $\mathrm{NaCl} 23.4 \%$ and $\mathrm{NaCl} / \mathrm{Na}$-Acetate $16.4 \%$ (Table 1 ) for the treatment of cerebral edema in patients with aneurysmal $\mathrm{SAH}$ and evolving hyperchloremia (serum $\mathrm{Cl}^{-} \geq 109 \mathrm{mmol} / \mathrm{L}$ ).

The primary objective of the A low ChloridE hyperTonic solution for brain Edema (ACETatE) study will be to assess longitudinal chloride serum change in aSAH patients treated with either $\mathrm{NaCl} 23.4 \%(30 \mathrm{~mL})$ or $\mathrm{NaCl} / \mathrm{Na}$-Acetate $16.4 \%$ (50 mL). Secondary outcomes will be: the rate of new-onset AKI according to KDIGO criteria [24]; all causes in-hospital mortality, including withdrawal of treatment or discharge to a hospice facility; and confirmation of a comparable effect of $\mathrm{NaCl} /$ Na-Acetate $16.4 \%$ and $\mathrm{NaCl} 23.4 \%$ for treatment of intracerebral hypertension. The latter will be assessed by:

Table 1 Composition of the two hypertonic solutions compared in the trial

\begin{tabular}{lll}
\hline & $\mathrm{NaCl}$ (standard treatment) group & NaCl/Na-Acetate (alternate treatment) group \\
\hline Solution components (per dose) & Sodium chloride & Sodium chloride and sodium acetate \\
Concentration (\%) & 23.4 & 16.4 \\
$\mathrm{NaCl} 23.4 \%$ pre-mixed solution $(\mathrm{mL})$ & 30 & 20 \\
$\mathrm{Na}-$ Acetate 3\% pre-mixed solution $(\mathrm{mL})$ & 0 & 30 \\
Volume $(\mathrm{mL})$ & 30 & 50 \\
Sodium content (mEq/dose) & 120 & 140 \\
Chloride content (mEq/dose) & 120 & 80 \\
Acetate content (mEq/dose) & 0 & 60 \\
\hline
\end{tabular}


1) effect on intracerebral pressure (ICP) when treatment indication is for elevated ICP; and 2) response in serum sodium concentration following administration.

\section{Study settings}

This will be a single-center trial in a major referral neurocritical care unit with more than 200 new admissions for SAH of any cause each year. All new aSAH admissions to the Neurocritical Care Unit at Emory University Hospital will be screened for eligibility by the intensive care unit (ICU) team upon arrival. Our experience, as well as data from the literature, suggest that non-aneurysmal SAH patients (e.g., idiopathic or "angio-negative") often have a more benign clinical course than aneurysmal SAH patients in terms of cerebral edema, vasospasm, and ultimately the need for osmotherapy [25, 26]. We will enroll only aneurysmal SAH patients to minimize heterogeneity. Consent will be obtained by the neurocritical care team affiliated with the study.

\section{Study design}

This is a prospective, double-blind, double-dummy pilot clinical trial. Patients will be enrolled within the first $36 \mathrm{~h}$ from admission to the ICU. Inclusion criteria include:

- Spontaneous SAH with an identified aneurysmal source as noted on neuroimaging.

- Age $\geq 18$ years

\section{Exclusion criteria include:}

- SAH related to non-aneurysmal etiology-e.g., other vascular source, trauma, negative workup ("angionegative"), etc.

- Patients who arrive in a brain-death state or in a devastating clinical status that will likely to lead to brain death or early withdrawal from curative treatment

- Patients who suffer from end-stage renal disease at baseline or who are currently receiving renal replacement therapy

- Known pregnancy

Figures 2 and 3 outline the study flow chart and schedule, respectively. A Standard Protocl Items: Recommandations for Clinical Interventional Trials (SPIRIT) checklist is also available (see Additional file 1). Patients will be eligible for enrollment up to $36 \mathrm{~h}$ after ICU admission, a time period during which the etiology of the SAH (aneurysmal versus non-aneurysmal) is usually validated, and surgical or endovascular treatment is completed.
All patients will initially receive standard SAH care [27]. Commencement and dose of hypertonic treatment $(\mathrm{NaCl} 23.4 \%)$ for cerebral edema will be at the discretion of the attending physician. Serum $\mathrm{Cl}^{-}$levels will be monitored daily for all patients. Patients will become eligible for randomization if their serum $\mathrm{Cl}^{-}$reaches $109 \mathrm{mmol} /$ $\mathrm{L}$ or above. Actual randomization will occur only when the attending physician decides to continue with hypertonic treatment.

For randomization to $\mathrm{NaCl}$ or the $\mathrm{NaCl} / \mathrm{Na}$-Acetate group (1:1 ratio), we will use random block sizes and will stratify by: 1) serum creatinine level on admission (normal vs. abnormal according to our clinical laboratory normal range); and 2) SAH Hunt and Hess score, i.e. low (1-2) vs. high (3-5) [28]. Randomization will be conducted centrally, under Emory's investigational drug service responsibility, to avoid potential unblinding of group allocation of the clinical team, who will not be able to access the allocation list until the end of the trial, specifically until the 90-day status is obtained for the last patient enrolled. In case the attending physician decides that the blinded treatment does not achieve its goals, an unblinded treatment will be initiated instead.

As the hypertonic $\mathrm{NaCl}$ and $\mathrm{NaCl} / \mathrm{Na}$-Acetate study solutions are not equal in volume, we have developed a double-blinded, double-dummy design in which all patients will receive the treatment dose in one bag and a second bag containing the placebo solution. Patients will blindly receive either: 1) $30 \mathrm{~mL} \mathrm{NaCl} \quad 23.4 \%$ IV piggyback (ivpb) plus a $50-\mathrm{mL}$ infusion of dummy solution (balanced electrolyte solution: Plasma-Lyte A) ivpb over $20 \mathrm{~min}$; or 2) $50 \mathrm{~mL} \mathrm{NaCl} / \mathrm{Na}$-Acetate16.4\% ivpb plus a 30-mL ivpb infusion of a dummy solution over $20 \mathrm{~min}$. There will be no other difference in the treatment of the patients. Both bags will be administered concurrently via separate ports of a central line.

After consent is obtained, patient demographic and clinical information will be collected. Study data will be stored and managed using REDCap, a HIPPA compatible secure database, hosted at Emory University [29]. Patient identity on REDCap will be coded to ensure patient anonymity. For each randomized patient that receives the study drug, we will use a specific charting aid to document medication administration and adverse events once per shift. A study safety and data monitoring committee has been established to review trial data once a year or upon recruiting half of the planned patients, whichever comes first, which consists of neurocritical care attendings not related to the trial and a biostatistician. The committee will evaluate differences in in-patient mortality as the main indication to terminate the trial, and will assess serious reported adverse effects.

We further plan to collect and store urine and serum samples daily as well as cerebrospinal fluid (CSF) 


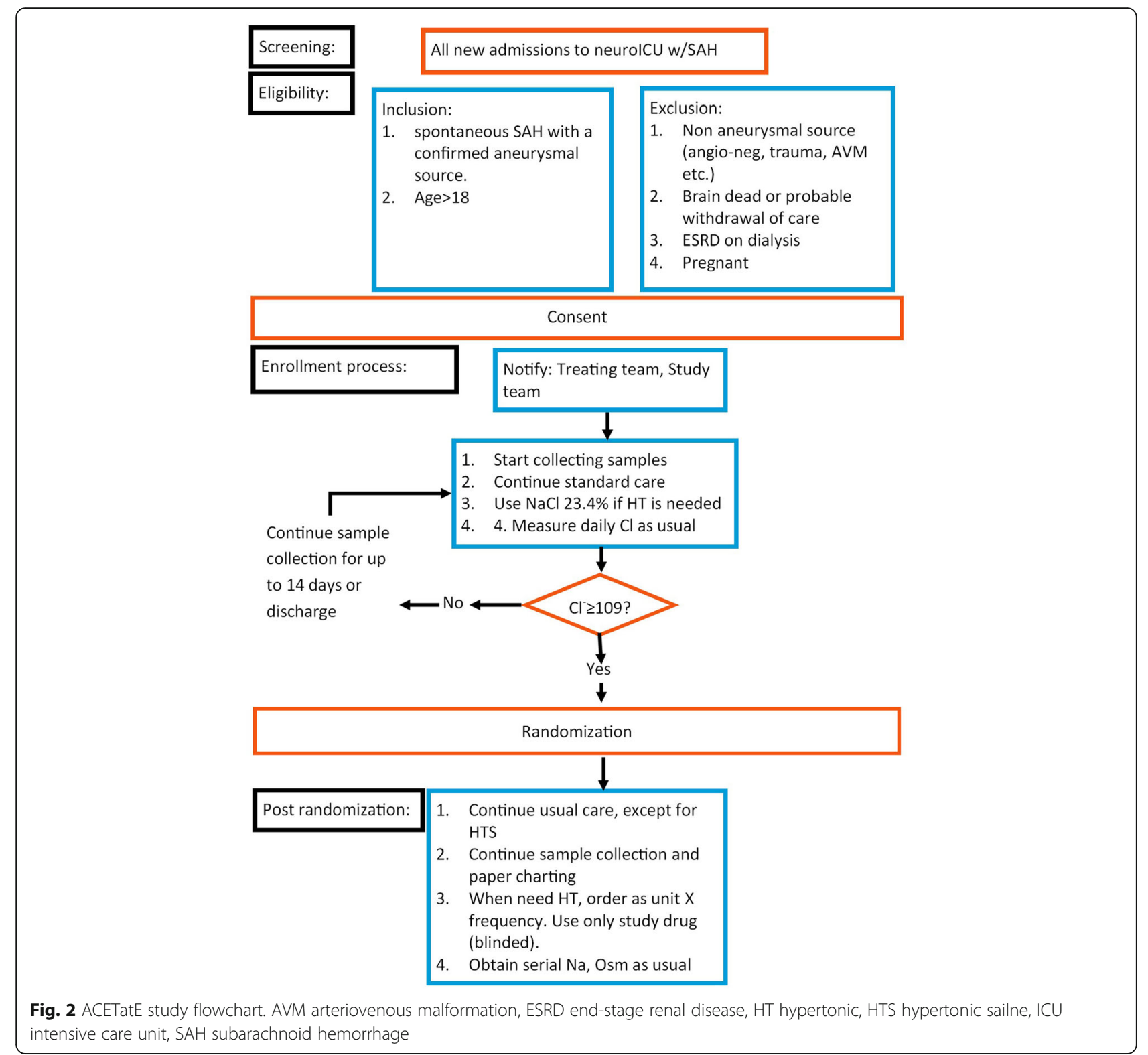

samples, if available, up to three times a week. These samples will be stored for future analysis and will not be part of the primary study analysis. Following patient discharge, we will assess their survival, disposition (e.g., home, long-term acute care, etc.) and functional capacity (measured by modified Rankin scale) at approximately 90 days post-bleed, either during a planned outpatient visit or by phone.

\section{Sample size and statistical analysis}

Based on our retrospective analysis previously mentioned [7], we anticipate a maximal change in serum $\mathrm{Cl}^{-}$ of $10 \mathrm{mmol} / \mathrm{L}$ for patients randomized to the $30-\mathrm{mL}$ $23.4 \% \mathrm{NaCl}$ group. In patients randomized to the $50-\mathrm{mL}$ $16.4 \% \mathrm{NaCl} / \mathrm{Na}$-Acetate group, we hypothesize that a maximal change in serum $\mathrm{Cl}^{-}$of $4 \mathrm{mmol} / \mathrm{L}$ will occur. By randomizing 60 patients for this pilot trial (30 patients per group), we will have a $63 \%$ power to detect a six-point difference in the change in serum $\mathrm{Cl}^{-}$levels ( $4 \mathrm{mmol} / \mathrm{L}$ vs. $10 \mathrm{mmol} / \mathrm{L}$ ) between treatment groups (two-sided test, type I error rate 0.05 ). The data analysis will follow the intent-to-treat principle.

To randomize 60 eligible patients with serum $\mathrm{Cl}^{-}$ levels of $109 \mathrm{mmol} / \mathrm{L}$ or greater who require hypertonic treatment, we will need to consent a higher number of patients. In our cohort analysis [7], only $15 \%$ of all patients did not develop serum $\mathrm{Cl}^{-}$levels $\geq 109 \mathrm{mmol} / \mathrm{L}$. Therefore, we will consent up to 100 patients and randomize the first 60 that meet our eligibility requirements. 


\begin{tabular}{|c|c|c|c|c|c|}
\hline & STUDY PE & RIOD & & & \\
\hline & Enrollment & Allocation & Post-allocation & Close-out & \\
\hline TIMEPOINT & Od & $0-14 d$ & ICU admission & Discharge & 90 days \\
\hline ENROLLMENT: & & & & & \\
\hline Eligibility screen & $\mathrm{x}$ & & & & \\
\hline Informed consent & $\mathrm{x}$ & & & & \\
\hline Sample collection & $x$ & & & & \\
\hline Allocation & & $X^{*}$ & & & \\
\hline $\begin{array}{l}\text { INTERVENTIONS: } \\
\text { Hypertonic } \\
\text { treatment as } \\
\text { needed }\end{array}$ & & & $x$ & & \\
\hline ASSESSMENTS: & & & & & \\
\hline $\begin{array}{l}\text { Daily labs and urine } \\
\text { output }\end{array}$ & $x$ & $x$ & $x$ & & \\
\hline $\begin{array}{l}\text { Functional outcome } \\
\text { assessment }\end{array}$ & & & & $x$ & $x$ \\
\hline
\end{tabular}

*Allocation or randomization will happen if a patient requires hypertonic $\mathrm{NaCl}$ treatment and had $\mathrm{Cl} \geq 109 \mathrm{mmol} / \mathrm{L}$

Fig. 3 Schedule of enrollment, interventions, and assessments. ICU intensive care unit

\section{Discussion}

We propose a double-blind, double-dummy, prospective clinical trial to compare the effect of two hypertonic saline solutions with different $\mathrm{Cl}^{-}$content on serum $\mathrm{Cl}^{-}$levels in patients with cerebral edema due to aSAH. Our immediate goal is to collect high-quality prospective data regarding the adverse effects, effectiveness, and feasibility of our current hypertonic solution dosing strategies. In the future, we plan to design a larger randomized trial.

This is the first trial to prospectively assess the relationship between the $\mathrm{Cl}^{-}$content of two hypertonic solutions with different $\mathrm{Cl}^{-}$content and their effect on serum electrolytes as well as renal function.

The question whether balanced IV fluid solutions, i.e., low $\mathrm{Cl}^{-}$solutions, improve patient outcome when compared with isotonic $\mathrm{NaCl}$ has been controversial for several years $[30,31]$. Although some studies have demonstrated associations between higher IV chloride content and AKI, recent prospective studies have produced conflicting results [18-20,32]. Failure to focus on specific patient populations, i.e., patients at risk for AKI, could be one reason for these inconsistent results.

Hypertonic solutions are, by definition, non-balanced and represent an extreme case of $\mathrm{IV} \mathrm{Cl}^{-}$exposure. In a recent retrospective study, we have demonstrated a relationship between hyperchloremia, the use of hypertonic solutions, and the development of AKI in patients with SAH. Unfortunately, our data did not reveal a dose-response relationship between $\mathrm{IV} \mathrm{Cl}^{-}$exposure and AKI [7]. However, our findings have allowed us to identify a group of SAH patients who are at risk for AKI. As only $8.5 \%$ of our patients with maximal serum $\mathrm{Cl}^{-}$concentrations $<109 \mathrm{mmol} / \mathrm{L}$ developed AKI, we consider serum $\mathrm{Cl}^{-}$concentrations $\geq 109 \mathrm{mmol} / \mathrm{L}$ as a risk factor for AKI in patients with $\mathrm{SAH}$, and propose a corresponding study design. So far, no clinical trial has based commencement of randomized treatment on the evolution or presence of a specific risk factor, such as hyperchloremia, when studying the effects of IV solutions with different $\mathrm{Cl}^{-}$content.

The ACETatE trial will allow for a direct assessment of the dose-response relationship between the IV solution and serum concentrations, for both sodium and chloride. We are following a pragmatic trial design, as there is no clear, widely accepted protocol for use of hypertonic solutions in patients with SAH. Dose and frequency of osmotherapy will be at the discretion of the attending physician. The treatment for study patients will be nearly identical to that of any other patient with SAH in our ICU. Treatment will 
only differ by the $\mathrm{Cl}^{-}$content of the hypertonic solution to which the patients will be randomized.

An important, potential limitation of our study is the comparison of two solutions with different volumes and $\mathrm{Na}^{+}$concentrations. Although the total $\mathrm{Na}^{+}$load will be lower in the more concentrated solution, the precise effects of $30 \mathrm{ml}$ of $23.4 \% \mathrm{Na}^{+}$solution versus those of $50 \mathrm{ml}$ of $16.4 \% \mathrm{Na}^{+}$solutions on serum osmolarity, serum sodium, and ICP remain unknown.

Another potential pitfall is insufficient enrollment due to the limitations of the informed consent process in critically ill patients [33]. First, patients are often unable to consent themselves due to the cerebral injury while a next of kin cannot be contacted in time. Second, patients or their families have great difficulty consenting for a trial given the seriousness of the illness and deciding on it within a relatively short period of time.

Even if we achieve our goal of patients, our power to detect the needed difference is only $63 \%$. These calculations have dictated the primary goal of preventing extreme hyperchloremia, and not AKI, which is too rare to change in a small, single-center trial.

However, the ACETatE trial, with all the mentioned limitations and possible confounding circumstances, will follow the changes in serum electrolyte concentration as a function of IV exposure. This high-quality information will help us to design a large-scale clinical trial which is desperately needed in the debate about the optimal $\mathrm{Cl}^{-}$ content in the IV solution [30, 31].

\section{Trial status}

This trial has been approved by the Emory University IRB (protocol version \#4, dated 6/8/2017, clinicaltrials.gov \#NCT03204955). Recruitment is ongoing.

\section{Additional file}

Additional file 1: SPIRIT 2013 checklist: recommended items to address in a clinical trial protocol and related documents. (DOC $122 \mathrm{~kb}$ )

\section{Abbreviations}

AKI: Acute kidney injury; CSF: Cerebrospinal fluid; ICP: Intracerebral pressure; IRB: Institutional Review Board; SAH: Subarachnoid hemorrhage

\section{Funding}

The study is funded in part by PHS grant UL1TR000454 from the Clinical and Translational Science Award program, National Institutes of Health, and the National Center for Advancing Translational Sciences. The funding body did not have any role in the design of the study and collection, analysis, and interpretation of data or in writing the manuscript.

\section{Availability of data and materials}

The datasets that will be generated and/or analyzed during the current study will be available from the corresponding author upon reasonable request. Results are expected to be published in the medical literature, and will be available for enrolled patients who would wish to learn about the outcome.

\section{Authors' contributions}

OfS worked on data analysis, trial design, funding, and drafting the manuscript. OwS worked on trial design, funding, and manuscript review. WHA worked on trial design and manuscript review. JJH worked on data analysis, power calculation, study design, manuscript drafting, and review. KS worked on trial design, funding, and manuscript review. All authors read and approved the final manuscript.

Ethics approval and consent to participate

The latter of Approval from Emory Univerist IRB was submitted to the journal Editor.

Consent for publication

Not applicable.

\section{Competing interests}

The authors declare that they have no competing interests.

\section{Publisher's Note}

Springer Nature remains neutral with regard to jurisdictional claims in published maps and institutional affiliations.

\section{Author details}

${ }^{1}$ Department of Neurology and Neurosurgery, Division of Neurocritical Care, Emory University Hospital and Emory School of Medicine, 1364 Clifton Road NE, Atlanta, GA 30322, USA. ²Department of Pharmacy, Emory University Hospital, 1364 Clifton Road NE, Atlanta, GA 30322, USA. ${ }^{3}$ Department of Biostatistics and Bioinformatics, Emory University, 1518 Clifton Road NE, Atlanta, GA 30322, USA. ${ }^{4}$ Department of Critical Care Medicine, Mayo Clinic, Phoenix, AZ 85054, USA

Received: 30 March 2018 Accepted: 20 October 2018

Published online: 14 November 2018

References

1. Rinkel GJ, van Gijn J, Wijdicks EF. Subarachnoid hemorrhage without detectable aneurysm. A review of the causes. Stroke. 1993;24:1403-9.

2. Feigin VL, Rinkel GJE, Lawes CMM, Algra A, Bennett DA, van Gijn J, Anderson CS. Risk factors for subarachnoid hemorrhage: an updated systematic review of epidemiological studies. Stroke. 2005;36:2773-80.

3. Linn FHH, Rinkel GJE, Algra A, van Gijn J. Incidence of subarachnoid hemorrhage: role of region, year, and rate of computed tomography: a meta-analysis. Stroke. 1996;27:625-9.

4. Rincon F, Rossenwasser RH, Dumont A. The epidemiology of admissions of nontraumatic subarachnoid hemorrhage in the United States. Neurosurgery. 2013:73:217-23.

5. Haley EC, Kassel NF, Torner JC. A randomized controlled trial of high-dose intravenous nicardipin in aneurysmal subarachnoid hemorrhage. JNS. 1993; 78(4):537-47.

6. Zacharia BE, Ducruet AF, Hickman ZL, Grobelny BT, Fernandez L, Schmidt JM, Narula R, Ko LN, Cohen ME, Mayer SA, Connolly ES. Renal dysfunction as an independent predictor of outcome after aneurysmal subarachnoid hemorrhage: a single-center cohort study. Stroke. 2009:40:2375-81.

7. Sadan O, Singbartl K, Kandiah P, Martin K, Samuels O. Hyperchloremia is associated with acute kidney injury in patients with subarachnoid hemorrhage. CCM. 2017;45(8):1382-8.

8. Claassen J, Carhuapoma JR, Kreiter KT, Du EY, Connolly ES, Mayer SA. Global cerebral edema after subarachnoid hemorrhage: frequency, predictors, and impact on outcome. Stroke. 2002;33:1225-32.

9. Kamel H, Navi B, Nakagawa K, Hemphill JC, Ko NU. Hypertonic $\mathrm{NaCl}$ versus mannitol for the treatment of elevated intracranial pressure: a meta-analysis of randomized clinical trials. Crit Care Med. 2001;39:554-9.

10. Kellum JA, Song M, Venkataraman R. Effects of hyperchloremic acidosis on arterial pressure and circulating inflammatory molecules in experimental sepsis. Chest. 2004;125:243-8.

11. Chowdhury AH, Cox EF, Francis ST, Lobo DN. A randomized, controlled, double-blind crossover study on the effects of $2-\mathrm{L}$ infusions of $0.9 \% \mathrm{NaCl}$ and Plasma-Lyte 148 on renal blood flow velocity and renal cortical tissue perfusion in healthy volunteers. Ann Surg. 2012;256:18-24. 
12. Reid F, Lobo DN, Willams RN, Roelsnfd BJ, Allison SP. (Ab)normal NaCl and physiological Hartmann's solution: a randomized double-blind crossover study. Clin Sci. 2003;104:17-24.

13. Neyra JA, Canepa-Escaro F, Li X, Manllo J, Adams-Huet B, Yee J, Yessayan L. Association of hyperchloremia with hospital mortality in critically ill septic patients. Crit Care Med. 2015; in press.

14. McCluskey SA, Karkouti K, Wijeysundera D, Minkovich L, Tait G, Beattie WS. Hyperchloremia after noncardiac surgery is independently associated with increased morbidity and mortality: a propensity-matched cohort study. Anesth Analg. 2013;117:412-21.

15. Yunos NM, Bellomo R, Hegarty C, Story D, Ho L, Bailey M. Association between a chloride-liberal vs chloride-restrictive intravenous fluid administration strategy and kidney injury in critically ill adults. JAMA. 2012; 308(15):1566-72.

16. Raghunathan K, Shaw A, Nathanson B, Stürmer T, Brookhart A, Stefan MS, Setoguchi S, Beadles C, Lindenauer PK. Association between the choice of IV crystalloid and in-hospital mortality among critically ill adults with sepsis. Crit Care Med. 2014;42:1585-91.

17. Krajewski ML, Raghunathan K, Paluszkiewicz SM, Schermer CR, Shaw AD. Meta-analysis of high- versus low-chloride content in perioperative and critical care fluid resuscitation. BJS. 2015;102:24-36.

18. Young P, Bailey M, Beasley R, Henderson S, Mackle D, McArthur C. Effect of a buffered crystalloid solution vs $\mathrm{NaCl}$ on acute kidney injury among patients in the intensive care unit (the SPLIT Randomized Clinical Trial). JAMA. 2015;314(16):1701-10.

19. Self WH, Semler MW, Wanderer JP, Wang L, Byrne DW, Collins SP, Slovis CM, Lindsell CJ, Ehrenfeld JM, Siew ED, Shaw AD, Bernard GR, Rice TW, Investigators SALT-ED. Balanced crystalloids versus saline in noncritically ill adults. N Engl J Med. 2018;378(9):819-28.

20. Semler MW, Self WH, Wanderer JP, Ehrenfeld JM, Wang L, Byrne DW, Stollings $J$, Kumar AB, Hughes CG, Hernandez A, Guillamondegui OD, May AK, Weavind L, Casey JD, Siew ED, Shaw AD, Bernard GR, Rice TW. SMART Investigators and the Pragmatic Critical Care Research Group. Balanced crystalloids versus saline in critically ill adults. N Engl. J Med. 2018;378(9):829-39.

21. Corry JJ, Varelas P, Abdelhak T, Morris S, Hawley M, Hawkins A, Jankowski M. Variable change in renal function by hypertonic $\mathrm{NaCl}$. World J Crit Care Med. 2014;3(2):61-7.

22. Kumar AB, Shi Y, Shotwell MS, Richards J, Ehrenfeld JM. Hypernatremia is a significant risk factor for acute kidney injury after subarachnoid hemorrhage: a retrospective analysis. Neurocrit Care. 2015;22:184-91.

23. Manzanares W, Aramendi I, Langlois PL, Biestro A. Hyponatremia in the neurocritical care patient: an approach based on current evidence. Med Int. 2015:39(4):234-43.

24. Kellum JA, Lameire N. Diagnosis, evaluation, and management of acute kidney injury: a KDIGO summary (part 1). Crit Care. 2013;17:204.

25. Sarabia R, Lagares A, Fernández-Alén JA, Arikan F, Vilalta J, Ibáñez J, Maillo A, Gabarros A, Domínguez J, Horcajadas A, Ballenilla F, Rodríguez-Boto G, Llacer JL, Arrese I, de la Lama A, Santamarta D, Delgado P, Muñoz MF. Idiopathic subarachnoid hemorrhage: a multicentre series of 220 patients. Neurocirugia (Astur). 2010;21(6):441-51.

26. Raya A, Zipfel GJ, Diringer MN, Dacey RG Jr, Derdeyn CP, Rich KM, Chicoine MR, Dhar R. Pattern not volume of bleeding predicts angiographic vasospasm in nonaneurysmal subarachnoid hemorrhage. Stroke. 2014:45(1):265-7.

27. Edlow JA, Figaji A, Samuels O. Emergency neurological life support: subarachnoid hemorrhage. Neurocrit Care. 2015;23(Suppl 2):S103-9.

28. Hunt WE, Hess RM. Surgical risk as related to time of intervention in the repair of intracranial aneurysms. J Neurosurg. 1968;28(1):14-20.

29. Harris PA, Taylor R, Thielke R, Payne J, Gonzalez N, Conde JG. Research electronic data capture (REDCap) — a metadata-driven methodology and workflow process for providing translational research informatics support. J Biomed Inform. 2009;42(2):377-81.

30. MacDonald N, Pearse RM. Are we close to the ideal intravenous fluid? Br J Anaesth. 2017;119(S1):i63-71.

31. Raghunathan K, Nailer $\mathrm{P}$, Konoske R. What is the ideal crystalloid? Curr Opin Crit Care. 2015;21(4):309-14.

32. Potura E, Lindner G, Biesenbach P, Funk GC, Reiterer C, Kabon B, Schwarz C, Druml W, Fleischmann $E$. An acetate-buffered balanced crystalloid versus 0. $9 \% \mathrm{NaCl}$ in patients with end-stage renal disease undergoing cadaveric renal transplantation: a prospective randomized controlled trial. Anesth Analg. 2015:120(1):123-9.
33. Scales DC. Research to inform the consent-to-research process. Intensive Care Med. 2013:39(8):1484-6.

\section{Ready to submit your research? Choose BMC and benefit from:}

- fast, convenient online submission

- thorough peer review by experienced researchers in your field

- rapid publication on acceptance

- support for research data, including large and complex data types

- gold Open Access which fosters wider collaboration and increased citations

- maximum visibility for your research: over $100 \mathrm{M}$ website views per year

At BMC, research is always in progress.

Learn more biomedcentral.com/submissions 